\title{
Unit per Gram per Hour
}

National Cancer Institute

\section{Source}

National Cancer Institute. Unit per Gram per Hour. NCI Thesaurus. Code C73775.

An arbitrary unit of substance rate expressed in unit(s) per gram per period of time equal to sixty minutes. 